\title{
Cardiac surgery after mediastinal radiation: Extent of exposure influences outcome
}

\author{
Albert S. Y. Chang, MD, ${ }^{a}$ Nicholas G. Smedira, MD, ${ }^{a}$ Catherine L. Chang, MD, ${ }^{\mathrm{b}}$ Monica M. Benavides, BS, \\ Ulf Myhre, MD, ${ }^{a}$ Jingyuan Feng, MS, ${ }^{c}$ Eugene H. Blackstone, MD, ${ }^{a, c}$ and Bruce W. Lytle, MD ${ }^{a}$
}

Supplemental material is available online.
From the Departments of Thoracic and Cardiovascular Surgery, ${ }^{\mathrm{a}}$ Radiation Oncology, ${ }^{\mathrm{b}}$ and Quantitative Health Sciences, ${ }^{\mathrm{c}}$ Cleveland Clinic, Cleveland, Ohio.

Read at the Thirty-second Annual Meeting of the Western Thoracic Surgical Society, Sun Valley, Idaho, June 21-24, 2006.

Received for publication June 23, 2006; revisions received Sept 18, 2006; accepted for publication Sept 29, 2006.

Address for reprints: Nicholas G. Smedira, MD, Kaufman Center for Heart Failure, Department of Thoracic and Cardiovascular Surgery, Cleveland Clinic, 9500 Euclid Ave/F24, Cleveland, OH 44195 (E-mail: smedirn@ccf.org).

J Thorac Cardiovasc Surg 2007;133:404-13 $0022-5223 / \$ 32.00$

Copyright (๑) 2007 by The American Association for Thoracic Surgery

doi:10.1016/j.jtcvs.2006.09.041
Objectives: Mediastinal radiation for thoracic malignancies uses multiple treatment fields and doses. We investigated whether more extensive radiation exposure is associated with more hospital complications and worse survival after cardiac surgery.

Methods: From January 2000 to January 2005, 230 patients underwent cardiac surgery after 3 levels of mediastinal radiation: extensive (Hodgkin disease, thymoma, and testicular cancer; $\mathrm{n}=70$ ), variable (eg, non-Hodgkin lymphoma and lung cancer; $\mathrm{n}=35$ ); and tangential (breast cancer; $\mathrm{n}=125$ ). Hospital complications were recorded prospectively, and time-related survival was assessed by patient follow-up (mean follow-up, $2.2 \pm 1.4$ years).

Results: Patients receiving extensive exposure were youngest (51 vs 64 vs 72 years), with the longest radiation-to-operation interval (25 vs 13 vs 14 years), and had the most diastolic dysfunction, left main stenosis of greater than $70 \%$ ( $21 \%$ vs $9 \%$ vs $8 \%$ ), and aortic regurgitation $(79 \%$ vs $54 \%$ vs $50 \%$ ). Patients receiving extensive and variable exposure had the poorest pulmonary function (percent predicted forced expiratory volume in 1 second, 57\% vs 54\% vs $67 \%$; percent predicted forced vital capacity, $56 \%$ vs $63 \%$ vs 66\%). All groups received a similar mix of cardiac procedures. Hospital deaths (13\% vs $8.6 \%$ vs $2.4 \%$ ) and respiratory complications (24\% vs $20 \%$ vs $9.6 \%)$ were higher after more extensive radiation, and survival was poorer (4-year survival, $64 \%$ vs $57 \%$ vs $80 \%$ ) than for patients receiving tangential radiation exposure, and it deviated more from expected matched-population life tables.

Conclusions: Among patients undergoing cardiac surgery after thoracic radiation, radiation exposure is heterogeneous, and therefore these patients cannot be managed and assessed as a single uniform cohort. Extensively irradiated patients are more likely to develop radiation heart disease, which increases perioperative morbidity and decreases short- and long-term survival.

$\mathrm{T}$ horacic radiation has been an effective treatment for cancers involving the mediastinum and thorax. However, patients so treated might experience subsequent cardiac disease and become candidates for cardiac surgery. ${ }^{1-3}$ It has been observed that patients receiving radiation before cardiac surgery, as a group, have poorer short- and long-term outcomes than those not receiving radiation. ${ }^{4-10}$ However, postradiation patients are a heterogeneous group in regard to the technique of radiation exposure and possibly in regard to the causation of their heart disease. Past studies combined patients into a single group and did not assess the effect of treatment fields and radiation dosing on outcomes. We hypothesized that patients receiving extensive thoracic radiation exposure have worse outcomes than those receiving less mediastinal exposure. Therefore we (1) contrasted patients, their heart disease, and radiation-related comorbidities according to the extent of radiation treatment; (2) characterized in-hospital complications and their risk factors; and 


$$
\begin{aligned}
& \text { Abbreviations and Acronyms } \\
& \begin{aligned}
\text { FEV }_{1} & =\text { forced expiratory volume in } 1 \text { second } \\
\text { ITA } & =\text { internal thoracic artery } \\
\text { LV } & =\text { left ventricular } \\
\text { RV } & =\text { right ventricular }
\end{aligned}
\end{aligned}
$$

(3) assessed time-related mortality and its risk factors in patients undergoing cardiac surgery after remote radiation therapy.

\section{Patients and Methods \\ Patients}

From January 2000 to January 2005, 15,074 cardiac operations were performed at Cleveland Clinic. Of these, 230 patients had received previous thoracic radiation for treatment of malignancy. Primary data were collected concurrently with patient care as part of the Cardiovascular Information Registry. We reviewed each patient's medical records to identify type of cancer treatment, including combined chemoradiotherapy and extent and timing of radiation. Expiration summaries and autopsy findings were reviewed to assign a mode of hospital death. Both Cardiovascular Information Registry data and data obtained from medical record review were preapproved for use in research by the institutional review board, such that patient consent was waived.

\section{Radiation Extent}

The majority of patients underwent radiation for breast cancer $(\mathrm{n}=125,55 \%)$, followed by Hodgkin disease $(\mathrm{n}=61,27 \%)$, non-Hodgkin lymphoma $(\mathrm{n}=12,5.2 \%)$, lung cancer $(\mathrm{n}=15$, $6.5 \%$ ), and other malignancies (testicular cancer, laryngeal cancer, esophageal cancer, thymoma, leukemia, sarcoma, and pulmonary cancer with unknown primary; $\mathrm{n}=17,7.4 \%$ ). Because exact radiation treatment field and dose were usually unavailable, we grouped patients into 3 categories according to presumed extent of cardiac radiation. During the study period, radiation therapy for Hodgkin disease, thymomas, and testicular cancer typically included extensive mediastinal radiation involving portions of the heart (extensive radiation group). Patients with other thoracic tumors (non-Hodgkin lymphoma; lung, esophageal, and laryngeal cancers; sarcoma; leukemia; and 1 pulmonary cancer with unknown primary) received varying doses of radiation to the mediastinum, heart, and surrounding structures (variable radiation group). Patients with breast cancer typically received peripheral radiation to the breast or chest wall, with less direct exposure of heart structures (tangential radiation group).

\section{Outcomes}

Early in-hospital complications assessed included mortality, respiratory insufficiency, renal failure, stroke, myocardial infarction, sepsis, and reoperation for bleeding, as defined for the Society of Thoracic Surgery National Database (Table E1).

Time-related survival was assessed by using Institutional Review Board-approved mailed or telephone questionnaires, with the patient's or a surviving family member's consent. Circumstances of death were elicited to the extent possible. The common closing date for vital status was July 20, 2004. Active follow-up was amplified when necessary by use of the Social Security Death Index, which was queried on January 20, 2005. ${ }^{11,12}$ Mean follow-up was $2.2 \pm 1.4$ years, with 505 patient-years of information available for analysis.

\section{Data Analysis}

Hospital events. Multivariable logistic regression was used to identify risk factors for postoperative events. Radiation extent and tumor type, demographics, symptoms, cardiac rhythm and function, details of the cardiac disease treated, noncardiac comorbidity, hemodynamics, and procedure variables were considered in the analysis (Table E2). Initial screening ensured that at least 5 events were associated with each candidate risk factor. Bootstrap bagging was used for variable selection, with automated analysis of 500 resampled data sets with a $P$ value of .05 or less for variable inclusion, followed by tabulating frequency of occurrence of both single factors and closely related clusters of factors. ${ }^{13,14}$ Variables with occurrence higher than $50 \%$ were considered reliably identified at a $P$ value of .05 or less.

Survival. Survival was estimated nonparametrically by using the Kaplan-Meier method and parametrically by using hazard function decomposition. ${ }^{15}$ It was compared with expected US population survival matched for age, sex, and race. Multivariable analysis of death was performed in the hazard function domain, using bootstrap bagging for variable selection. ${ }^{15}$

\section{Presentation}

Categoric variables are presented as frequencies and percentages. Continuous variables are summarized as means and standard deviations. Asymmetric $68 \%$ confidence limits are equivalent to \pm 1 standard error.

\section{Results}

\section{Radiation Extent}

Patients receiving extensive radiation were the youngest and had the longest interval between radiation treatment and cardiac surgery, the highest preoperative central venous pressures, the greatest diastolic dysfunction, the smallest hearts, and the highest prevalence of pericarditis, left main coronary artery stenosis, and aortic regurgitation (Table 1). ${ }^{16}$ The variable radiation group had the highest prevalence of severe chronic obstructive pulmonary disease, smokers, and renal insufficiency, with the highest preoperative creatinine level. Both groups had higher heart rates and pulmonary artery diastolic pressures and were more likely than the tangential group to have ischemic mitral valve regurgitation. The tangential radiation group was composed entirely of women, who were the oldest patients and had the highest prevalence of degenerative mitral valve disease and highest preoperative predicted forced expiratory volume in 1 second $\left(\mathrm{FEV}_{1}\right)$.

Operations performed were generally similar among the groups (Table 2). Among patients with $50 \%$ or greater stenosis of the left anterior descending coronary artery undergoing coronary artery bypass grafting $(\mathrm{n}=95)$, only 
TABLE 1. Patient characteristics

\begin{tabular}{|c|c|c|c|c|}
\hline \multirow[b]{2}{*}{ Variable } & \multicolumn{3}{|c|}{ Radiation extent, mean \pm SD or No. $(\%$ of $n)$} & \multirow[b]{2}{*}{$P$ value } \\
\hline & Extensive $(\mathrm{n}=70)$ & Variable $(n=35)$ & Tangential $(n=125)$ & \\
\hline \multicolumn{5}{|l|}{ Demographics } \\
\hline Age (y) & $51 \pm 13$ & $64 \pm 12$ & $72 \pm 8.8$ & $<.0001$ \\
\hline Women & $33(47)$ & $12(34)$ & $125(100)$ & $<.0001$ \\
\hline \multicolumn{5}{|l|}{ Cancer-related comorbidity } \\
\hline Radiation to operation (y) & $25 \pm 9.6$ & $13 \pm 8.9$ & $14 \pm 12$ & $<.0001$ \\
\hline Chemotherapy* & $36 / 51(71)$ & $22 / 28(79)$ & $43 / 67(64)$ & .4 \\
\hline \multicolumn{5}{|l|}{ Hemodynamics } \\
\hline Heart rate (beats $\left.\cdot \min ^{-1}\right)$ & $94 \pm 13$ & $93 \pm 12$ & $87 \pm 12$ & .0008 \\
\hline Cardiac index $\left(\mathrm{L} \cdot \min ^{-1} \cdot \min ^{-2}\right)$ & $2.7 \pm 0.89(\mathrm{n}=23)$ & $2.2 \pm 0.40(n=12)$ & $2.4 \pm 0.73(n=43)$ & .12 \\
\hline Central venous pressure $(\mathrm{mm} \mathrm{Hg})$ & $13 \pm 5.0$ & $11 \pm 5.2$ & $10 \pm 4.6$ & .006 \\
\hline PA diastolic pressure $(\mathrm{mm} \mathrm{Hg})$ & $22 \pm 7.0$ & $22 \pm 7.7$ & $20 \pm 7.1$ & .03 \\
\hline \multicolumn{5}{|l|}{ LV structure and function } \\
\hline Diastolic dysfunction & & & & $<.0001$ \\
\hline None/abnormal relaxation (stage 1) & $8(30)$ & $9(53)$ & $47(87)$ & \\
\hline Pseudonormal (stage 2) & $15(56)$ & $5(29)$ & $4(74)$ & \\
\hline Restrictive (stage 3) & $4(15)$ & $3(17)$ & $3(5.6)$ & \\
\hline Restrictive-irreversible (stage 4) & $0(0)$ & $0(0)$ & $0(0)$ & \\
\hline Intraventricular septal thickness $(\mathrm{cm})$ & $1.1 \pm 0.25$ & $1.3 \pm 0.39$ & $1.3 \pm 0.34$ & .001 \\
\hline Posterior wall thickness $(\mathrm{cm})$ & $1.03 \pm 0.25$ & $1.06 \pm 0.22$ & $1.16 \pm 0.24$ & .0007 \\
\hline Mass index $\left(\mathrm{g} \cdot \mathrm{m}^{-2}\right)$ & $94 \pm 31$ & $120 \pm 46$ & $118 \pm 41$ & .0003 \\
\hline End-diastolic volume index $\left(\mathrm{mL} \cdot \mathrm{m}^{-2}\right)$ & $54 \pm 22$ & $62 \pm 21$ & $55 \pm 24$ & .18 \\
\hline Ejection fraction, echo $(\%)$ & $49 \pm 14$ & $44 \pm 15$ & $50 \pm 13$ & .2 \\
\hline \multicolumn{5}{|l|}{ Pericardium } \\
\hline Pericarditis & $13(19)$ & $2(5.7)$ & $6(4.8)$ & .004 \\
\hline \multicolumn{5}{|l|}{ Coronary artery disease } \\
\hline Left main disease $(\geq 50 \%)$ & $19(28)$ & $6(18)$ & $19(16)$ & .12 \\
\hline \multicolumn{5}{|l|}{ Valve disease } \\
\hline Aortic stenosis & $34(49)$ & $12(34)$ & $58(46)$ & .4 \\
\hline Aortic regurgitation & $55(79)$ & $19(54)$ & $63(50)$ & .0005 \\
\hline Mitral stenosis & $6(9)$ & $3(8.6)$ & $13(10)$ & .9 \\
\hline Mitral regurgitation & $60(86)$ & $28(80)$ & $98(78)$ & .5 \\
\hline Ischemic*† & $6 / 57(11)$ & $4 / 27(15)$ & $2 / 100(2.0)$ & .02 \\
\hline Degenerative ${ }^{*}$ & $18 / 57(32)$ & $3 / 27(11)$ & $46 / 100(46)$ & .003 \\
\hline Tricuspid regurgitation & $52(74)$ & $23(66)$ & $85(68)$ & .6 \\
\hline \multicolumn{5}{|l|}{ Pulmonary comorbidity } \\
\hline Severe COPD (\%)‡ & $6(8.6)$ & $7(20)$ & $4(3.2)$ & .003 \\
\hline Percent predicted FEV 1 & $57 \pm 19(n=27)$ & $54 \pm 18(n=11)$ & $67 \pm 19(n=40)$ & .04 \\
\hline Percent predicted FVC & $56 \pm 19(n=27)$ & $63 \pm 20(n=11)$ & $66 \pm 18(n=40)$ & .13 \\
\hline \multicolumn{5}{|l|}{ Other comorbidities } \\
\hline Tobacco use & $35(51)$ & $27(77)$ & $62(50)$ & .01 \\
\hline Renal insufficiency & $2(2.9)$ & $4(11)$ & $2(1.6)$ & .02 \\
\hline Creatinine $\left(\mathrm{mg} \cdot \mathrm{dL}^{-1}\right)$ & $0.92 \pm 0.26$ & $1.23 \pm 0.86$ & $0.93 \pm 0.39$ & .03 \\
\hline
\end{tabular}

$S D$, Standard deviation; $P A$, pulmonary artery; $L V$, left ventricular; $C O P D$, chronic obstructive pulmonary disease; FEV ${ }_{1}$, forced expiratory volume in 1 second; $F V C$, forced vital capacity. *Because of incomplete information, denominator is shown. $\dagger$ Defined as at least moderate pure mitral valve regurgitation in patients having a documented prior myocardial infarction, with wall motion anomalies, and no gross mitral leaflet pathology or papillary muscle rupture. ${ }^{16}$ Defined as $\mathrm{FEV}_{1}$ of less than $50 \%$, room air $\mathrm{PaO}_{2}$ of less than $60 \%$, or $\mathrm{PaCO}_{2}$ of greater than $50 \%$.

$44(46 \%)$ received internal thoracic artery (ITA) grafts, and these were similarly distributed among groups $(P=.8)$.

\section{In-hospital Complications and Their Risk Factors}

There were 15 (6.5\%) hospital deaths. The most frequent mode of death was multisystem organ failure, often pre- cipitated by respiratory failure (Table 3 ). Hospital death was higher in the extensive and variable radiation groups than in the tangential group (Table 4); after adjusting for other factors, risk was highest in the extensive radiation group $(P=.02$, Table E3). These patients were nearly 3.5 times more likely to experience respiratory insuffi- 
TABLE 2. Operation performed*

\begin{tabular}{|c|c|c|c|c|}
\hline \multirow[b]{2}{*}{ Procedure } & \multicolumn{3}{|c|}{ Radiation extent } & \multirow[b]{2}{*}{$P$ value } \\
\hline & Extensive, $n(\%$ of 70$)$ & Variable, $\mathbf{n}(\%$ of 35$)$ & Tangential, $\mathbf{n}$ ( $\%$ of 125 ) & \\
\hline CABG & $36(52)$ & $22(63)$ & $69(55)$ & .5 \\
\hline ITA uset & $9 / 22(41)$ & $9 / 19(47)$ & $26 / 54(48)$ & .8 \\
\hline AV replacement & $39(56)$ & $15(45)$ & $56(45)$ & .3 \\
\hline AV repair & $5(7.1)$ & $0(0)$ & $1(0.8)$ & .02 \\
\hline MV replacement & $19(27)$ & $7(20)$ & $23(18)$ & .4 \\
\hline MV repair & $19(27)$ & $9(26)$ & $26(21)$ & .6 \\
\hline TV replacement & $0(0)$ & $0(0)$ & $3(2.4)$ & .7 \\
\hline TV repair & $11(16)$ & $3(8.6)$ & $19(15)$ & .6 \\
\hline Pericardectomy & $2(2.9)$ & $2(5.7)$ & $2(1.6)$ & .4 \\
\hline Aortic surgery & $5(7.1)$ & $2(5.7)$ & $12(9.6)$ & .7 \\
\hline Reoperation & $20(29)$ & $13(37)$ & $25(20)$ & .09 \\
\hline Circulatory arrest & $7(10)$ & $1(2.9)$ & $9(7.2)$ & .4 \\
\hline
\end{tabular}

$\overline{C A B G}$, Coronary artery bypass grafting; ITA, internal thoracic artery; $A V$, aortic valve; $M V$, mitral valve; $T V$, tricuspid valve. *Procedures are not mutually exclusive. $\dagger$ In patients with $50 \%$ or greater stenosis of left anterior descending coronary artery. Because of incomplete information, denominator is shown.

ciency $(P=.006$, Table E3). Intensive care unit and postoperative lengths of stay were similar among groups (Table 4).

\section{Time-related Mortality and Its Risk Factors}

At 1,2, and 4 years postoperatively, unadjusted survival for the tangential radiation group $(88 \%, 84 \%$, and $80 \%$ at 1,2 , and 4 years, respectively) was higher than that of the ex- tensive $(78 \%, 70 \%$, and $64 \%)$ and variable $(73 \%, 64 \%$, and $57 \%)$ exposure groups $(P=.003)$ and more nearly matched expected survival for the general population (Figure 1).

Both the extensive and variable radiation groups had twice the adjusted risk of death of the tangential radiation group (Table 5), although the smaller number of patients in the variable exposure group resulted in larger uncertainty. In addition, patients with severe pulmonary or

\section{TABLE 3. Modes of hospital death and autopsy findings}

\begin{tabular}{|c|c|c|}
\hline $\begin{array}{l}\text { Patient no. and } \\
\text { radiation extent }\end{array}$ & Mode of death & Autopsy findings \\
\hline \multicolumn{3}{|l|}{ Extensive } \\
\hline 1 & Sepsis, low cardiac output, respiratory failure, MSOF & $\begin{array}{l}\text { Bilateral pulmonary emboli, cirrhosis; bilateral pulmonary } \\
\text { congestion }\end{array}$ \\
\hline 2 & Mediastinitis, stroke, MSOF & $\begin{array}{l}\text { Gram-negative suppurative mediastinitis; bilateral } \\
\text { pulmonary congestion, remote pulmonary embolus }\end{array}$ \\
\hline 3 & Primary graft dysfunction after heart-lung transplantation & \\
\hline 4 & Respiratory failure, MSOF & \\
\hline 5 & Respiratory failure commencing with pleural effusion, MSOF & \\
\hline 6 & Pneumonia, MSOF & \\
\hline 7 & Pneumonia & \\
\hline 8 & Pneumonia & \\
\hline 9 & Cardiac failure & \\
\hline \multicolumn{3}{|l|}{ Variable } \\
\hline 1 & Respiratory failure, MSOF & \\
\hline 2 & Cardiac failure, MSOF & \\
\hline 3 & Pneumonia, MSOF & Radiation pneumonitis with bilateral pneumonia \\
\hline \multicolumn{3}{|l|}{ Tangential } \\
\hline 1 & Respiratory failure, sternal dehiscence, MSOF & \\
\hline 2 & Cardiac arrest, anoxic encephalopathy & $\begin{array}{l}\text { Remote and recent transmural and subendocardial left } \\
\text { ventricular infarcts }\end{array}$ \\
\hline 3 & $\begin{array}{l}\text { Respiratory arrest, mucous plugging, anoxic } \\
\text { encephalopathy }\end{array}$ & \\
\hline
\end{tabular}


TABLE 4. Postoperative in-hospital complications

\begin{tabular}{|c|c|c|c|c|}
\hline \multirow[b]{2}{*}{ Complication } & \multicolumn{3}{|c|}{ Radiation extent } & \multirow[b]{2}{*}{$P$ value } \\
\hline & Extensive, $n(\%$ of 70$)$ & Variable, $n(\%$ of 35$)$ & Tangential, $\mathbf{n}$ (\% of 125 ) & \\
\hline Hospital death & $9(13)$ & $3(8.6)$ & $3(2.4)$ & .01 \\
\hline Renal failure & $6(8.6)$ & $5(14)$ & 4 (3.2) & .04 \\
\hline Sepsis & $9(13)$ & $5(14)$ & $10(8.0)$ & .4 \\
\hline Stroke & $4(5.7)$ & $0(0)$ & $1(0.8)$ & .06 \\
\hline Reoperation for bleeding & $4(5.7)$ & $3(8.6)$ & $9(7.2)$ & .8 \\
\hline Sternal wound infection* & $3 / 67(4.5)$ & $1 / 34(2.9)$ & $4 / 122(3.3)$ & .9 \\
\hline ICU length of stay $(d) \dagger$ & $2(1,13)$ & $2(1,21)$ & $3(1,7)$ & .36 \\
\hline Postoperative length of stay (d) $\dagger$ & $8(5,36)$ & $9(6,29)$ & $8(6,17)$ & .9 \\
\hline
\end{tabular}

$I C U$, Intensive care unit. *Denominator is number of patients having sternotomy. †Median (15th, 85th percentiles).

renal disease, lower hematocrit values, increased central venous pressure, enlarged left atrium, smaller left ventricular (LV) mass, or longer myocardial ischemic time were at higher risk of mortality (Table 5). Reoperation per se was not identified as a risk factor, nor was use of hypothermic circulatory arrest.

Of 39 deaths occurring after hospital discharge, mode of death could not be ascertained in 24 . Of the remaining 15 , mode of death was cardiac related in 5, pulmonary related in 5 , renal failure in 1 , multisystem organ failure in 1 , and cancer related in 3 .

\section{Discussion}

\section{Thoracic Radiation Exposure}

Published studies examining outcomes of cardiac surgery after thoracic radiation have not differentiated patients by intensity and fields of radiation received. ${ }^{4-10}$ This study demonstrates the importance of this distinction.

Radiation groups were created according to generally accepted treatment approaches. In patients with thymoma, seminoma, and Hodgkin disease, radiation fields at that time traditionally encompassed the entire mediastinum (Figure E1). ${ }^{17-19}$ In contrast, breast cancer radiation fields have been tangential to the base of the breast, with minimal exposure to the heart (Figure E2). The remaining cancers in this study were included in the variable radiation group because of inhomogeneity of radiation field design caused by tumor location and evolving historical changes in treatment approach.

\section{Principal Findings}

In essence, patients receiving tangential radiation have cardiac pathology and respond to surgical therapy like nonirradiated patients, and extensively and variably irradiated patients manifest cardiac injury that has been commonly referred to as radiation heart disease. The prominence of pulmonary dysfunction preoperatively and particularly postoperatively has led us to conclude that a more appropriate term is radiation heart and lung (cardiopulmonary) disease.

The well-known microcirculatory injury caused by radiation leads to an assortment of progressive cardiac and pulmonary pathologies, including pericarditis, pericardial effusion, accelerated coronary artery arteriosclerosis (especially ostial lesions), myocardial fibrosis, calcification of the fibrous skeleton of the heart (ie, radiation heart disease), pneumonitis, and lung fibrosis. ${ }^{20-25}$ Fewer than $10 \%$ of our patients were diagnosed as having pericarditis, and only 6 underwent pericardectomy, suggesting that constrictive pericarditis is an infrequent manifestation of radiation heart and lung disease.

Radiation heart disease produces heart failure symptoms with preserved LV function and is classified as a secondary restrictive cardiomyopathy. ${ }^{26}$ Most of our patients had heart failure symptoms in the presence of normal LV function, and more extensively irradiated patients had higher central venous pressures and pulmonary artery pressures, enlarged left atria, worse LV diastolic function, and lower LV enddiastolic volume indices, all of which are consistent with radiation heart disease. Conversely, the tangential group had more typical heart disease with simply a history of previous radiation.

Radiation pulmonary injury results in restrictive lung function, which is found predominantly in extensively irradiated patients, whereas variably irradiated patients were frequently smokers with moderate-to-severe chronic obstructive pulmonary disease, and tangentially exposed women had only mildly reduced $\mathrm{FEV}_{1}$ and forced vital capacity, possibly related to kyphoscoliosis. Although smoking and musculoskeletal changes might play a role, radiation for Hodgkin disease and lung and breast cancers is known to irreversibly impair pulmonary function. ${ }^{27-31}$ 

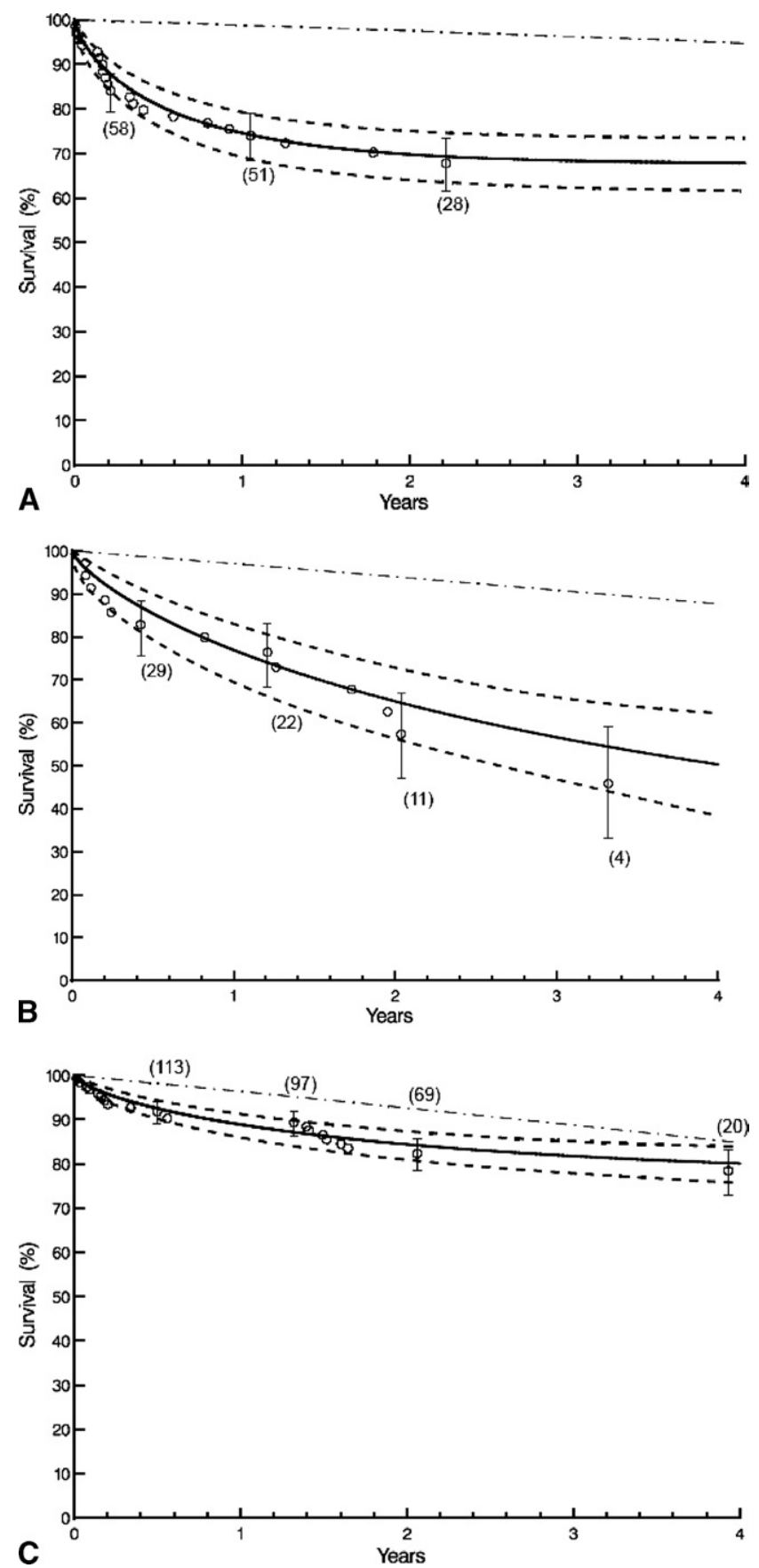

Figure 1. Survival after cardiac surgery in patients having prior thoracic radiation exposure. Each symbol represents a death, vertical bars are $68 \%$ confidence limits representing \pm 1 standard error, and numbers in parentheses represent patients alive and being traced. The solid line is the parametric estimate enclosed within dashed confidence limits. The dash-dot-dash line is survival of the age-, race-, and sex-matched US population. A, Extensive radiation group. B, Variable radiation group. C, Tangential radiation group.
TABLE 5. Incremental risk factors for death

\begin{tabular}{lclc}
\hline Risk factor & Coefficient \pm SE & $\begin{array}{c}\boldsymbol{P} \\
\text { value }\end{array}$ & $\begin{array}{c}\text { Reliability } \\
(\%)\end{array}$ \\
\hline $\begin{array}{l}\text { Radiation extent* } \\
\quad \text { Extensive }\end{array}$ & $0.74 \pm 0.35$ & .034 & 60 \\
$\quad$ Variable & $0.64 \pm 0.41$ & .12 & \\
Higher central venous & $0.050 \pm 0.023$ & .03 & 56 \\
$\quad$ pressure & & & \\
Higher left atrial volume† & $0.15 \pm 0.063$ & .02 & 46 \\
Lower left ventricular mass $\ddagger$ & $0.91 \pm 0.23$ & .0001 & 89 \\
Lower hematocrit§ & $1.9 \pm 0.78$ & .02 & 63 \\
Severe COPD & $0.90 \pm 0.40$ & .02 & 51 \\
Higher BUN\| & $0.054 \pm 0.022$ & .02 & 68 \\
Longer myocardial ischemic & $0.24 \pm 0.078$ & .002 & 60 \\
$\quad$ timeף & & & \\
\hline
\end{tabular}

$S E$, Standard error; COPD, chronic obstructive pulmonary disease; BUN, blood urea nitrogen. *Relative to tangential radiation. †Left atrial volume/ 50 , squared transformation. $\$$ Left ventricular mass/260, inverse transformation. $\S$ Hematocrit/40, inverse transformation. ||Blood urea nitrogen/20, squared transformation. IIMyocardial ischemic time/80, squared transformation.

\section{In-hospital Complications}

Mortality and morbidity were high in irradiated patients. Tangentially irradiated patients fared best. Sternal wound infections were uncommon and occurred equally among the 3 radiation exposure groups, but prevalence was higher than expected among nonirradiated patients and unaffected by use of the ITA.

Respiratory dysfunction, manifesting as pneumonia, intractable pleural effusion, and reintubation for poor ventilatory mechanics, was a frequent precursor to multisystem organ failure among our patients who died. There is likely an important ongoing pulmonary debility that continues well after the cardiac disease has been palliated. This might result from a progressive decrease in chest wall compliance, phrenic nerve and diaphragm dysfunction, intractable pleural effusion, and possibly pulmonary fibrosis.

The exact role of radiation lung injury (found in 1 of 4 patients at autopsy) remains uncertain, but it appears that reduced preoperative pulmonary function (radiation or smoking induced), decreased postoperative pulmonary mechanics, and pulmonary congestion (found in 2 of 4 patients at autopsy) caused by increased left atrial pressures from LV diastolic dysfunction may partially explain early surgical mortality and morbidity.

\section{Time-related Survival}

More extensive thoracic radiation exposure was associated with poorer time-related survival that was substantially less than that expected in the general population. The dose effect, risk factors for death, and paucity of cancer-related deaths during follow-up suggest a causal link between both cardiac and pulmonary radiation damage and prognosis. 
High resting heart rate and the risk factor of small $\mathrm{LV}$ mass together suggest that stroke volume is fixed, both preoperatively and postoperatively, as a result of the restrictive cardiomyopathy. Increased central venous pressure as a risk factor also suggests a component of right ventricular (RV) dysfunction. Few studies, ours included, have focused specifically on radiation effects on RV function. The resulting decrease in RV output leads to decreased LV preload in patients already sensitive to filling conditions. Biventricular dysfunction and diastolic heart failure could explain the worse outcomes.

\section{Limitations}

Details of cancer stage, radiation fields, and doses and chemotherapy regimens were not available and might have altered our results. This was a single-institution study, but spanned a short interval during which patient selection criteria and management strategies were rather uniform. We were unable to quantify LV diastolic dysfunction, although in most patients it was graded qualitatively by echocardiographers. We have no information about long-term progression of radiation effects on cardiac and pulmonary dysfunction after surgical intervention. Many times, it was not possible to elicit secure information about mode of late death, and there were few autopsies.

\section{Inferences About Clinical Management}

Indications for operation. We use standard indications for surgical intervention in these patients, but believe symptoms must be present before intervening. We could not identify hemodynamic or pulmonary function values below which successful conventional surgery would be precluded, but have recently questioned whether patients with multiple cardiac problems, reduced RV or LV function, restrictive or constrictive hemodynamics, or undergoing reoperation might be better served by heart or heart-lung transplantation. A small series of patients undergoing transplantation sheds little light on this issue. ${ }^{32}$ Although at increased lifetime risk of recurrent cancer, the few patients dying from cancer during follow-up suggests that immunosuppression would be safe. However, incisional and bronchial or tracheal anastomotic healing might make this a less-than-ideal solution.

Intraoperative management. Median sternotomy, thought to be less morbid than a thoracotomy, may profoundly impair respiratory mechanics. ${ }^{33,34}$ Bauer and colleagues ${ }^{35}$ found that 4 days after a ministernotomy or standard sternotomy, both $\mathrm{FEV}_{1}$ and forced vital capacity decreased by $50 \%$ from preoperative values and only slowly returned to normal. Thoracotomy is unlikely to be a better alternative. Aggressive preoperative smoking cessation, pulmonary rehabilitation, and draining of pleural effusions might be beneficial. Perhaps a thorough assessment of diaphragmatic function by means of fluoroscopic challenge (sniff test) could be of use to define high-risk patients.

During the study, most hearts were protected with cold, blood-based antegrade and retrograde cardioplegia. This method of myocardial protection, compared with antegradeonly or intermittent aortic clamping, has been associated with a decrease of early diastolic function in normal hearts. ${ }^{36}$ Use of hypothermia might also impair diastolic more than systolic function. ${ }^{37}$ Although it is impossible to separate the association of longer ischemic time with sicker patients requiring more complex operations, the possibility remains that irradiated hearts are more sensitive to ischemia, mode of myocardial protection, and temperature, leading to increased postoperative diastolic impairment. For patients requiring isolated revascularization, off-pump procedures might be a better alternative.

At a minimum, cardiac operations need to be well planned and executed. This includes use of the ITA and often valve replacement. Infrequent use of the left ITA was unanticipated; the primary authors have routinely used it. Although angiographic assessment of the ITA is used, it is not routine. Chest wall radiation for breast cancer does not preclude use of either the right or left ITA. We acknowledge the advantages of valve repair and lament the difficulties posed by postoperative anticoagulation; however, like Handa and associates, ${ }^{4}$ we favor definitive therapy at the initial operation to reduce ischemic times and need for reoperation.

Postoperative management. Because postoperative stroke volume is invariably fixed, maintaining adequate cardiac output requires higher than usual filling pressures and heart rates, with little benefit from inotropic therapy. Medical regimens for diastolic heart failure, including $\beta$-blockers, angiotensin-converting enzyme inhibitors, angiotensin receptor blockade, diuretics, and aldosterone antagonists, are limited and often ineffective. Use of a selective phosphodiesterase inhibitor III, such as milrinone, might be beneficial because of positive lusitropic and pulmonary vasodilatory properties, bronchodilatory action, and increase of diaphragmatic contractility.

\section{Conclusions}

We have demonstrated that extent of exposure among patients who have received thoracic radiation for cancer is variable, and therefore these patients cannot be managed and assessed as a single uniform cohort. Short- and longterm survival is diminished in those who are extensively irradiated, and complications are frequent. Treating these patients remains a great challenge; recent modifications in radiation techniques might reduce future cardiac and pulmonary injury.

We thank Songua Lin for statistical programming; Angela York for database construction; Tanya Ashinhurst for registry 
assistance; Karen Mrazeck for follow-up of patients; Arlene Hann, Stacie Lavin, Lisa Loncaric, and Kevin Pronty for collecting data concurrently with patient care; and Tess Parry for editorial assistance.

\section{References}

1. Basavaraju SR, Easterly CE. Pathophysiological effects of radiation on atherosclerosis development and progression, and the incidence of cardiovascular complications. Med Phys. 2002;29:2391-403.

2. Glanzmann C, Kaufmann P, Jenni R, Hess OM, Huguenin P. Cardiac risk after mediastinal irradiation for Hodgkin's disease. Radiother Oncol. 1998;46:51-62.

3. Hancock SL, Tucker MA, Hoppe RT. Factors affecting late mortality from heart disease after treatment of Hodgkin's disease. JAMA. 1993; 270:1949-55.

4. Handa N, McGregor CG, Danielson GK, Orszulak TA, Mullany CJ, Daly RC, et al. Coronary artery bypass grafting in patients with previous mediastinal radiation therapy. $J$ Thorac Cardiovasc Surg. 1999;117:1136-42.

5. Handa N, McGregor CG, Danielson GK, Daly RC, Dearani JA, Mullany CJ, et al. Valvular heart operation in patients with previous mediastinal radiation therapy. Ann Thorac Surg. 2001;71:1880-4.

6. Crestanello JA, McGregor CG, Danielson GK, Daly RC, Dearani JA, Orszulak TA, et al. Mitral and tricuspid valve repair in patients with previous mediastinal radiation therapy. Ann Thorac Surg. 2004;78: 826-31.

7. Reber D, Birnbaum DE, Tollenaere P. Heart diseases following mediastinal irradiation: surgical management. Eur J Cardiothorac Surg. 1995;9:202-5

8. Nasso G, Canosa C, De Filippo CM, Modugno P, Anselmi A, Gaudino $\mathrm{M}$, et al. Thoracic radiation therapy and suitability of internal thoracic arteries for myocardial revascularization. Chest. 2005;128:1587-92.

9. Veeragandham RS, Goldin MD. Surgical management of radiationinduced heart disease. Ann Thorac Surg. 1998;65:1014-9.

10. Hicks GL Jr. Coronary artery operation in radiation-associated atherosclerosis: long-term follow-up. Ann Thorac Surg. 1992;53:670-4.

11. Boyle CA, Decoufle P. National sources of vital status information: extent of coverage and possible selectivity in reporting. Am J Epidemiol. 1990;131:160-8.

12. Newman TB, Brown AN. Use of commercial record linkage software and vital statistics to identify patient deaths. J Am Med Inform Assoc. 1997:4:233-7.

13. Breiman L. Bagging predictors. Machine Learning. 1996;24:123-40.

14. Blackstone EH. Breaking down barriers: helpful breakthrough statistical methods you need to understand better. J Thorac Cardiovasc Surg. 2001;122:430-9.

15. Blackstone EH, Naftel DC, Turner ME Jr. The decomposition of time-varying hazard into phases, each incorporating a separate stream of concomitant information. J Am Stat Assoc. 1986;81:615-24.

16. Gillinov AM, Wierup PN, Blackstone EH, Bishay ES, Cosgrove DM, White $\mathbf{J}$, et al. Is repair preferable to replacement for ischemic mitral regurgitation? J Thorac Cardiovasc Surg. 2001;122:1125-41.

17. Zagars GK, Pollack A. Radiotherapy for stage II testicular seminoma. Int J Radiat Oncol Biol Phys. 2001;51:643-9.

18. Hoppe RT. Lymphoma and hematologic malignancies: Hodgkin's disease. In: Perez CA, Brady LW, Halperin EC, et al, editors. Principles and practice of radiation oncology. 4th ed. Philadelphia: Lippincott Williams \& Wilkins; 2004. p. 2043.

19. Eng TY, Scarbrough TJ, Thomas CR. Mediastinum and trachea. In: Perez CA, Brady LW, Halperin EC, et al, editors. Principles and practice of radiation oncology. 4th ed. Philadelphia: Lippincott Williams \& Wilkins; 2004. p. 1255.

20. Schultz-Hector S. Radiation-induced heart disease: review of experimental data on dose response and pathogenesis. Int J Radiat Biol. 1992:61:149-60.

21. Veinot JP, Edwards WD. Pathology of radiation-induced heart disease: a surgical and autopsy study of 27 cases. Hum Pathol. 1996;27:766-73.
22. Heidenreich PA, Hancock SL, Lee BK, Mariscal CS, Schnittger I. Asymptomatic cardiac disease following mediastinal irradiation. $J$ Am Coll Cardiol. 2003;42:743-9.

23. Adams MJ, Hardenbergh PH, Constine LS, Lipshultz SE. Radiationassociated cardiovascular disease. Crit Rev Oncol Hematol. 2003;45: 55-75.

24. Lee PJ, Mallik R. Cardiovascular effects of radiation therapy: practical approach to radiation therapy-induced heart disease. Cardiol Rev. 2005;13:80-6.

25. Arsenian MA. Cardiovascular sequelae of therapeutic thoracic radiation. Prog Cardiovasc Dis. 1991;33:299-311.

26. Leung DY, Klein A. Restrictive cardiomyopathy: diagnosis and prognostic implications. In: Ott CM, editor. Practice of clinical echocardiography. Philadelphia: WB Saunders; 1974. p. 474.

27. Lund MB, Kongerud J, Nome O, Abrahamsen AF, Bjortuft O, Forfang $\mathrm{K}$, et al. Lung function impairment in long-term survivors of Hodgkin's disease. Ann Oncol. 1995;6:495-501.

28. Ooi GC, Kwong DL, Ho JC, Lock DT, Chan FL, Lam WK, et al. Pulmonary sequelae of treatment for breast cancer: a prospective study. Int J Radiat Oncol Biol Phys. 2001;50:411-9.

29. Mehta V. Radiation pneumonitis and pulmonary fibrosis in non-smallcell lung cancer: pulmonary function, prediction, and prevention. Int $J$ Radiat Oncol Biol Phys. 2005;63:5-24.

30. Miller KL, Zhou SM, Barrier RC Jr, Shafman T, Folz RJ, Clough RW, et al. Long-term changes in pulmonary function tests after definitive radiotherapy for lung cancer. Int J Radiat Oncol Biol Phys. 2003;56: 611-5.

31. Nieder C, Jeremic B, Astner S, Molls M. Radiotherapy-induced lung toxicity: risk factors and prevention strategies. Anticancer Res. 2003; 23:4991-8.

32. Handa N, McGregor CG, Daly RC, Dearani JA, Edwards BS, Frantz $\mathrm{RP}$, et al. Heart transplantation for radiation-associated end-stage heart failure. Transpl Int. 2000;13:162-5.

33. Ragnarsdottir M, Kristjansdottir A, Ingvarsdottir I, Hannesson P, Torfason B, Cahalin L. Short-term changes in pulmonary function and respiratory movements after cardiac surgery via median sternotomy. Scand Cardiovasc J. 2004;38:46-52.

34. Kristjansdottir A, Ragnarsdottir M, Hannesson P, Beck HJ, Torfason B. Respiratory movements are altered three months and one year following cardiac surgery. Scand Cardiovasc J. 2004;38:98-103.

35. Bauer M, Pasic M, Ewert R, Hetzer R. Ministernotomy versus complete sternotomy for coronary bypass operations: no difference in postoperative pulmonary function. J Thorac Cardiovasc Surg. 2001; 121:702-7.

36. Casthely PA, Shah C, Mekhjian H, Swistel D, Yoganathan T, Komer $\mathrm{C}$, et al. Left ventricular diastolic function after coronary artery bypass grafting: a correlative study with three different myocardial protection techniques. J Thorac Cardiovasc Surg. 1997;114:254-60.

37. Fischer UM, Cox CS Jr, Laine GA, Mehlhorn U, Allen SJ. Mild hypothermia impairs left ventricular diastolic but not systolic function. J Invest Surg. 2005;18:291-6.

\section{Discussion}

Dr Thoralf M. Sundt (Rochester, Minn). Well done, Dr Chang. A very nicely presented article. My colleagues and I from the other clinic share your concern about both the short- and long-term outcomes of these patients. We are seeing more and more of these folks, and it is really a tough population with which to deal. If I understand your data correctly, given the choice from the menu of radiation-treated patients on whom to operate, I should pick the tangential ones and leave the extensive ones to my junior colleagues. Unfortunately, most of the time, we have to deal with the cases that we are served up, and accordingly, I have some specific questions for you that are perhaps more relevant as we face patient by patient in the clinic.

With regard to the individuals having tangential radiation, you mentioned some of this in your article, which I appreciate you 
sending to me. Could you comment on the use of the ITA ipsilateral to the radiation? I have quite frankly not used the ITA on the side of the radiation; this is almost an absolute rule for me. That is probably the only population in which I do not use the ITA to the left anterior descending coronary artery, and I would like your comments. What is your practice, and do you have any data about late ITA patency if the ITA has been irradiated?

A second question, focusing more on the patients receiving extensive radiation, who are the more problematic, you present something of a paradox. You argue for a definitive operation and I agree with that, the redo-as miserable as the first operation is - the redo is really, really tough, and yet ischemic time was one of the risk factors, so how do you balance that? What are your indications, for example? How much aortic regurgitation will you tolerate? When is the aortic regurgitation enough to warrant prolonging the ischemic time to subject the patient to an aortic valve replacement, which incidentally is a nontrivial exercise in these patients?

How do you handle the mitral valve in these patients? Repair versus replacement - it can be a problem if they leak after a repair and you are faced with the challenge of whether to do a rerepair or perform a transplantation. Pericardiectomy-how often did these patients undergo pericardiectomy, and do you ever do a prophylactic pericardiectomy? That is a frequent problem in these radiation-treated patients.

Finally, with regard to your suggestion about transplantation, these patients are very tough as redos on the transplant list as well, and I wonder what guidelines you currently use to triage them up front. It seems we have an attitude today to give everybody a shot with a conventional operation and if that fails to refer them on to transplantation. As one of the transplant surgeons at my institution, I am a little bit more circumspect about that. The redo is really unpleasant for these.

Thank you very much, and I thank the association for the opportunity to open the discussion on this article.

Dr Chang. Thank you, Dr. Sundt, for your comments and questions. In terms of internal thoracic artery use, we found that it was used surprisingly less often than our normal coronary revascularization practice pattern. In fact, barely half the eligible patients received an internal thoracic artery graft. We do no think tangential breast radiation precludes use of the internal thoracic artery. Studies from other institutions have shown conflicting results. Some authors state that despite radiation, the ipsilateral internal thoracic artery can be used, whereas others state that it cannot.

In terms of late patency, we have few angiographic studies, in common with everybody else.

For the extensive patients, one must balance longer myocardial ischemic times against definitive operations. What we try to do is aim for a definitive operation. If the valve can be easily repaired, we repair it. If there is any doubt, we believe replacement is the best option. Thus, for example, we believe that a rapid definitive operation is better than multiple pump runs in order to try to salvage a leaking valve. Whether or not the longer myocardial ischemic time can be balanced out by the one-time definitive operation has not yet been clarified.

Pericardectomy was performed in only 6 patients. Pericarditis was present in less than $10 \%$ of patients. Thus, we do not perform prophylactic pericardectomy. This does not seem to have been a problem, but it warrants careful follow-up.

In terms of transplantation, this was an issue brought up by Dr. Lytle recently. Although we usually try to give everyone a shot at conventional surgery, we have been wondering if heart or heartlung transplantation might be better to avoid redo operations. These patients have already had radiation. They have had their tissue planes obliterated, and their tissues are not normal. Trying to do an anastomosis, especially a bronchial or tracheal anastomosis, in this radiated field can be challanging. Performing a redo operation on top of that would certainly make it a high-risk procedure. We have not extended our practice pattern to going straight to transplantation, but it is something we are considering.

Currently, our indications for surgery are essentially the same as for nonirradiated patients, although we prefer patients who are more symptomatic; we do not just look at their physiologic abnormalities.

Dr James Mark (Stanford, Calif). Well done. Nice presentation. Dr Chang has brought an important problem to our attention and that is the aftermath of radiation to the chest. The patients to whom he refers must have had chemotherapy as well, at least some of them, and that treatment modality has its own problems. A few weeks ago, Dr Saul Rosenberg, a senior medical oncologist at Stanford-that means he is as old as I am-gave a medical grand rounds in which he reviewed the 45-year experience of the treatment of Hodgkin disease at Stanford using first radiotherapy alone and then radiotherapy combined with chemotherapy. Their group, spearheaded originally by Dr Henry Kaplan, who introduced the linear accelerator into clinical use, has been religious in their adherence to clinical trials and have found that by judicious tweaking of radiotherapy ports and dosages and by changing chemotherapy combinations to include smaller doses of more drugs, they can maintain a high tumor control rate while minimizing the side effects. For example, the present chemotherapy regimen includes small doses of 7 drugs in the treatment of Hodgkin disease. Mediastinal complications such as we have heard about today are not the only deleterious effects of radiotherapy. We have all seen malignant tumors of the chest wall in radiated fields, and the side effects of chemotherapy are too numerous and too diffuse to even talk about today. Dr Chang tells us about a relatively short follow-up period, 2 years plus, in these patients. I know that the Cleveland Clinic group will remain vigilant in looking for additional problems as time goes on. Some years ago, we reported an increase in postoperative cardiac problems in patients who underwent preoperative radiation for lung cancer. Has Dr Chang studied this group at all?

Thank you very much.

Dr Chang. Thank you, Dr. Mark. Stanford has been one of the leaders in the treatment of Hodgkin disease. In our conclusions, we also have recognized that it is important to pay careful attention to what radiation fields have been used as well as what chemotherapy treatments were given, as cancer treatments are constantly evolving. Over the last 20 years, treatment of Hodgkin disease, as Dr. Mark pointed out, has changed. It used to entail larger radiation fields, but now involves less radiation and more chemotherapy. Most of the patients in our study were treated about 20 years ago. However, 20 years from now or even 10 years from now, patients presenting for cardiac surgery who have previously had treatment 
for Hodgkin disease will be different, and their extent of radiation may be different as well.

We do not have specific information on chemotherapy. We know that about two-thirds to three-quarters of the patients did have chemotherapy, but because most were treated at outside institutions, we did not have specific data.

We did not look specifically at lung cancer as a subgroup, because only 15 patients had it. Rather, they were investigated in the variable radiation group.

Dr Donald Low (Seattle, Wash). Dr. Chang, very good article. Clearly the extensive and variable groups are at greatest risk for complications and outcomes, which are worse than seen in the general population. With the experience you have just had, do you think the tangential radiation group is at any substantial increased risk for complications, or is their risk equivalent to that of the general population?

Dr Chang. That is a good point and one we were trying to emphasize: Cardiac disease in the tangential group is most likely related to the natural history of conventional heart disease rather than to the radiation itself. Those patients more closely match the general population and probably should not be considered "radiation heart disease" patients. They do have some changes in pulmonary function, probably making them a slightly worse risk than nonirradiated patients, because the lung is partially involved in tangential radiation. These patients do have some pathologic changes in their lungs, but certainly minor compared with the two other groups.

Dr D. Craig Miller (Stanford, Calif). Nice work. I was tweaked by Dr Sundt's question and heard your response that you do not think much of parietal pericardiectomy the first time around if you are going to embark on a conventional cardiac operation for the extensive group. I share your group's reticence and maybe we are not doing the right thing here. We are kidding ourselves and maybe transplantation in the suitable candidates-not all these people are with the radiation fibrosis to the lung and the esophagus and what not-but we have something that Stanford calls "Stinson's rule," which is probably not published, but it has been around for 30 years. In this extensive group, with which we have all too much experience, Ed pointed out early, 20 or 25 years ago, that even though the parietal pericardium might look normal, it probably is very wise to do a phrenic to phrenic pericardiectomy anteriorly, at least the first time you are there, for left main disease or AVR or mitral or whatever because these people come back and haunt you badly. That is if you are going to embark on a conventional cardiac operation as a first shot, which is getting less and less attractive.

Dr Chang. Thank you for your comment. That may be the best way to go, but our experience with pericardectomy in general suggests that post-radiation patients account for less than $10 \%$ of that population. 
TABLE E1. Postoperative complications

\begin{tabular}{ll}
\hline Complication & \multicolumn{1}{c}{ Definition } \\
\hline Respiratory insufficiency & $\begin{array}{c}\text { Combination of reintubation, extended time intubated ( }>72 \mathrm{~h} \text { ), readmission to ICU for respiratory } \\
\text { complications } \\
\text { New onset requiring hemodialysis } \\
\text { Renal failure }\end{array}$ \\
$\begin{array}{l}\text { Verified by computed tomographic scan or magnetic resonance imaging, with symptoms that did not } \\
\text { resolve by time of discharge }\end{array}$ \\
Intraoperative or postoperative infarction verified by electrocardiogram and enzymes (CK-MB or troponin \\
Sepsis & T)
\end{tabular}

ICU, Intensive care unit; $C K-M B$, creatine kinase MB fraction.

\section{TABLE E2. Variables used in multivariable analyses}

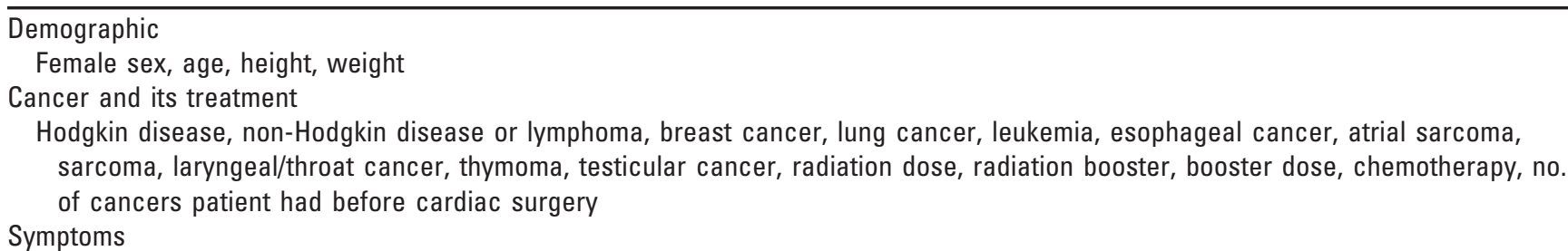

New York Heart Association class, Canadian angina class, emergency operation

Resting hemodynamics (at anesthesia induction)

Heart rate, mean arterial pressure, central venous pressure, pulmonary artery systolic and diastolic pressures, cardiac output

Cardiac structure and function

Preoperative pleural effusion grade $(0=$ none, $1=$ small, $2=$ moderate, $3=$ large $)$; adhesions $(0=$ none, $1=$ light, $2=$ moderate, $3=$ dense); pericardial thickening $(0=$ none, $1=$ mild, $2=$ moderate, $3=$ severe $)$; pericardial calcification $(0=$ none, $1=$ mild, $2=$ moderate, $3=$ severe); mitral calcification $(0=$ none, $1=$ mild, $2=$ moderate, $3=$ severe); left atrial diameter; LV diastolic function rank; LV posterior wall thickness; intraventricular septal thickness; LV relative wall thickness; LV mass; LV mass index; LV end-diastolic volume index; LV end-systolic volume index; LV fractional shortening; LV ejection fraction; cause of valve disease (rheumatic, degenerative, ischemic, endocarditis); valve pathology (calcification, fibrosis, chordal and papillary muscle pathology, restricted leaflet motion); aortic, mitral, and tricuspid valve regurgitation and stenosis (presence and grades); aortic annulus diameter

Ventricular function

Graded LV dysfunction, LV ejection fraction, previous myocardial infarction

Coronary artery disease

No. of coronary artery systems diseased $(\geq 50 \%), \geq 50 \%$ and $\geq 70 \%$ stenoses of left main coronary artery, left anterior descending coronary artery, circumflex coronary artery, and right coronary artery

Cardiac rhythm

Atrial fibrillation/flutter, complete heart block, ventricular arrhythmia

Noncardiac comorbidity

Smoking; history of peripheral vascular disease, carotid disease, hypertension, diabetes (insulted treated, oral hypoglycemic diet), renal disease, COPD, COPD with pulmonary function $\angle 75 \%$ of predicted value, COPD treated, COPD grade (mild, moderate, severe), pulmonary hypertension, blood urea nitrogen, creatinine, bilirubin, hematocrit, cholesterol, triglycerides

Procedure

CABG; use of ITA graft (single, bilateral); number of ITA grafts; CABG performed during index operation; aortic, mitral, and tricuspid valve repair or replacement; myocardial ischemic time

$L V$, Left ventricular; COPD, chronic obstructive pulmonary disease; $C A B G$, coronary artery bypass grafting; ITA, internal thoracic artery. 
TABLE E3. Risk factors for in-hospital complications

\begin{tabular}{|c|c|c|c|}
\hline Complication and risk factor for death & Coefficient \pm SE & $P$ value & Reliability (\%) \\
\hline \multicolumn{4}{|l|}{ Death } \\
\hline Extent of radiation* & & & 31 \\
\hline Extensive & $1.6 \pm 0.7$ & .02 & \\
\hline Variable & $0.37 \pm 1.05$ & .7 & \\
\hline Longer myocardial ischemic time & $0.27 \pm 0.088$ & .002 & 71 \\
\hline \multicolumn{4}{|l|}{ Respiratory insufficiency } \\
\hline Extent of radiation* & & & 33 \\
\hline Extensive & $1.3 \pm 0.46$ & .006 & \\
\hline Variable & $0.54 \pm 0.58$ & .4 & \\
\hline Higher central venous pressureł & $0.35 \pm 0.088$ & $<.0001$ & 78 \\
\hline Left circumflex system disease & $1.5 \pm 0.51$ & .004 & 59 \\
\hline \multicolumn{4}{|l|}{ Renal failure } \\
\hline Extent of radiation* & & & 6 \\
\hline Extensive & $1.3 \pm 0.91$ & .2 & \\
\hline Variable & $0.44 \pm 1.1$ & .7 & \\
\hline Longer myocardial ischemic time & $0.26 \pm 0.11$ & .02 & 46 \\
\hline Severe COPD & $2.7 \pm 0.82$ & .0009 & 54 \\
\hline Higher BUN§ & $0.36 \pm 0.13$ & .005 & 50 \\
\hline \multicolumn{4}{|l|}{ Sepsis } \\
\hline Extent of radiation* & & & 4 \\
\hline Extensive & $0.15 \pm 0.59$ & .8 & \\
\hline Variable & $-0.60 \pm 0.88$ & .5 & \\
\hline Longer myocardial ischemic timet & $0.28 \pm 0.098$ & .004 & 73 \\
\hline Higher central venous pressureł & $0.29 \pm 0.1$ & .005 & 64 \\
\hline Lower mean arterial pressure $\|$ & $3.4 \pm 1.5$ & .02 & 48 \\
\hline Severe COPD & $1.8 \pm 0.74$ & .02 & 46 \\
\hline \multicolumn{4}{|l|}{ Return to OR for bleeding } \\
\hline Extent of radiation* & & & 2 \\
\hline Extensive & $-0.23 \pm 0.69$ & .7 & \\
\hline Variable & $0.15 \pm 0.81$ & .9 & \\
\hline Higher central venous pressureף & $0.12 \pm 0.047$ & .008 & 68 \\
\hline 1-System disease $>50 \%$ & $1.5 \pm 0.61$ & .01 & 46 \\
\hline
\end{tabular}

$S E$, Standard error; $C O P D$, chronic obstructive pulmonary disease; $B U N$, blood urea nitrogen; $O R$, operating room. *Relative to tangential radiation. $\dagger$ Aortic clamp time/80, exponential transformation. $\ddagger$ Central venous pressure/10, squared transformation. $§ B l o o d$ urea nitrogen/20, squared transformation. $\|$ Mean arterial pressure/90, inverse transformation. \[Central venous pressure/10, exponential transformation. 


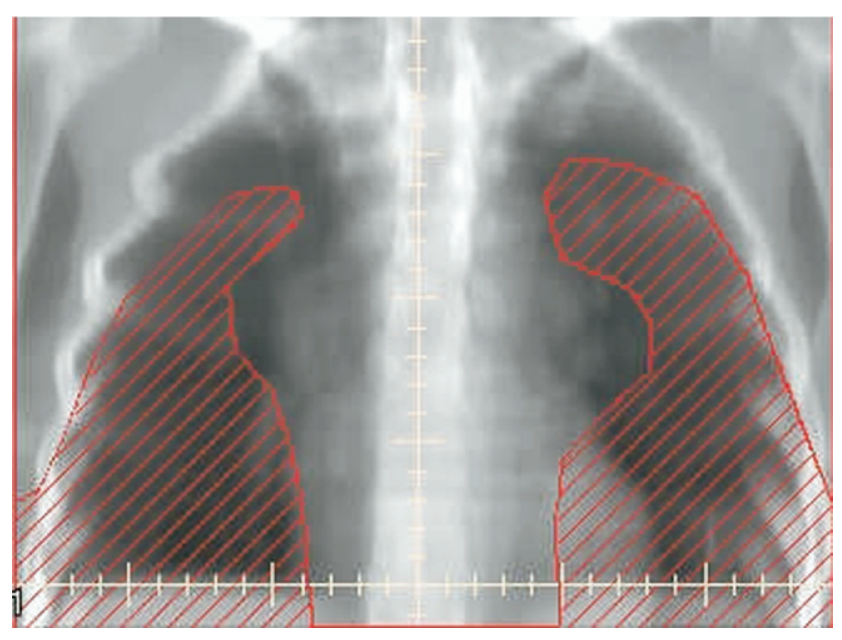

Figure E1. Example of fields used for radiation of Hodgkin disease, including the mediastinum, apices of the lung, axillae, and neck. Lung blocks (hatched areas) are used to shield part of the lungs during treatment, but the heart and mediastinum are included in the radiation field. 